\title{
Reestructuraciones subjetivas en las sociedades laborales: separación y exclusión de socios ${ }^{1}$
}

\author{
Rosario Cañabate $\mathrm{Pozo}^{2}$
}

Recibido: 2 de octubre de 2017 / Aceptado: 14 de febrero de 2018

Resumen. Se estudia el derecho de separación y la exclusión de socios en las sociedades laborales destacando sus connotaciones propias por motivo de su configuración especial como sociedades capitalistas integradas en el ámbito de la economía social. El artículo 16 de la Ley 44/2015, de 14 de octubre, de Sociedades Laborales y Participadas (en adelante, LSLyP) regula, por primera vez, la separación y la exclusión de socios, constituyendo dicha materia una de las principales novedades de la nueva regulación al no existir, hasta ese momento, una regulación especial en el ámbito relativo al derecho de separación, así como tampoco en el correspondiente a la exclusión de socios en las sociedades laborales. Tanto la separación como la exclusión de socios suponen reajustes en la estructura interna societaria posibilitando la continuidad de la organización societaria laboral, pero sin que dichos procesos sean ajenos a múltiples interrogantes necesitados de una adecuada respuesta jurídica dentro del ámbito, más general, de las reestructuraciones subjetivas en las sociedades laborales, que no han sido suficientemente abordados en su nueva regulación.

Palabras clave: Sociedad Laboral; Derecho de Separación; Exclusión de Socios.

Claves Econlit: K22; K29; P12.

\section{[en] Subjective reestructuring in the worker-owned companies: separation and exclusion of partners}

\begin{abstract}
This paper studies the right of separation and exclusion in the worker owned companies from the distinctive connotations of the capitalist societies comprised in the social economy. The article 16 of Law 44/2015, of October 14th, on Labor and Investee Companies (onwards we'll use the Spanish acronym LSLyP) regulates, for the first time, the right of separation and the right of exclusion. This is one of its main novelties because there is not any other special regulation in the partner's right of separation and exclusion in the worker owned companies. Both separation and exclusion of shareholders embody corporate internal structure adjustments facilitating continuity of work corporate organization; but these processes need a tailored treatment, within the more general scope of subjective restructuring in worker owned companies, that have not been adequately addressed in their new regulation.
\end{abstract}

Keywords: Labor Society; Right of Separation; Exclusion of Partners.

1 El presente trabajo se realiza en el marco del Proyecto de Investigación "Integración cooperativa y reestructuraciones responsables. Mecanismos de creación de empleo e incremento de productividad empresarial", referencia DER2013-48864-C2-1-P. Ministerio de Economía y Competitividad, cuyo investigador principal es Carlos Vargas Vasserot.

2 Universidad de Almería, España

Dirección de correo electrónico: rcpozo@ual.es 
Sumario. 1. Introducción. 2. El derecho de separación de los socios en las sociedades laborales: la descalificación de la sociedad. 3. El derecho de separación de los socios no trabajadores de las sociedades laborales en caso de falta de distribución de dividendos. 4. Causas estatutarias de separación en las sociedades laborales. 5. La exclusión de socios en las sociedades laborales. 6 . Efectos para la sociedad laboral derivados del ejercicio del derecho de separación y de la exclusión de socios. 7. Referencias bibliográficas.

Cómo citar: Cañabate Pozo, R. (2017) Reestructuraciones subjetivas en las sociedades laborales: separación y exclusión de socios. REVESCO. Revista de Estudios Cooperativos, Monográfico, $\mathrm{N}^{\circ}$ 126, pp. 32-56. DOI: 10.5209/REVE.59765.

\section{Introducción}

La separación y la exclusión de socios constituyen dos novedades importantes del nuevo régimen jurídico para las sociedades laborales (artículo 16 LSLyP). En tal sentido, se destaca la omisión que, al respecto, existía en la derogada Ley 4/1997, de 24 de marzo, de Sociedades Laborales (disposición derogatoria única de la LSLyP). Dicha omisión sólo ha significado la aplicación a las sociedades laborales del régimen jurídico de las sociedades capitalistas conforme a la forma jurídica correspondiente (sociedad anónima o sociedad de responsabilidad limitada) de la sociedad laboral (Disposición Final Primera Ley 4/1997).

Con tales consideraciones, el artículo 16 LSLyP regula, ahora, lo que sigue: 1. "La pérdida de la calificación de la sociedad como laboral podrá ser causa legal de separación por parte del socio. Si la descalificación fuera consecuencia de un acuerdo adoptado en Junta General, el derecho de separación corresponderá a los socios que no votaron a favor del acuerdo". 2. "El derecho de separación en caso de falta de distribución de dividendos previsto en el artículo 348 bis del texto refundido de la Ley de Sociedades de Capital, aprobado por el Real Decreto Legislativo 1/2010, de 2 de julio, no será de aplicación a los socios trabajadores de la sociedad laboral". 3. "La sociedad laboral podrá excluir al socio que incumpla las obligaciones previstas en esta ley en materia de transmisión de acciones y participaciones, o realice actividades perjudiciales para los intereses de la sociedad y por las que hubiera sido condenado por sentencia firme a indemnizar a la sociedad los daños y perjuicios causados. Las acciones o participaciones de los socios separados o excluidos deberán ser ofrecidas a los trabajadores de la sociedad con contrato de trabajo por tiempo indefinido, conforme a lo previsto en el artículo 6 de esta ley. Las acciones o participaciones no adquiridas deberán ser amortizadas mediante reducción del capital social". 4. "En el plazo máximo de cuatro meses a partir de la recepción del escrito por el que el socio comunica que ejercita su derecho de separación previsto en el apartado 1 de este artículo, del acuerdo de la Junta General por el que se decide la exclusión del socio, o de la notificación de la resolución judicial firme dictada al respecto, el socio separado o excluido tendrá derecho a obtener en el domicilio social el valor de sus acciones o participaciones, trasmitidas o amortizadas".

Ese es el único precepto de la LSLyP referido, en exclusiva, a la separación y a la exclusión de socios y, por lo tanto, el que constituye nuestro ámbito de análisis principal, aunque existen otros artículos en la LSLyP relacionados con dicha materia y que, asimismo, serán tomados en consideración al estudiar el régimen 
jurídico de la separación y de la exclusión de socios en las sociedades laborales. Al igual que sucedía con la extinta regulación de las sociedades laborales, la Disposición Final Tercera de la LSLyP sanciona el carácter de derecho supletorio de las normas correspondiente a las sociedades anónimas o de responsabilidad limitada, según el tipo de la sociedad laboral de que se trate. Al respecto, con carácter general, la doctrina ha advertido la dificultad que tal remisión general encierra por la singularidad de las sociedades laborales como empresarios integrados dentro del ámbito de la economía social que exige la internalización de fines sociales y de interés general (Paniagua, 2015a; Paniaguab, 2015; Fernández de la Gándara, 2010) frente a las genuinas sociedades capitalistas en las que están presentes sus propios principios configuradores (Verdú, 2016, García, 2013, García, 2017). Con carácter especial, respecto de la materia relativa a la separación y a la exclusión de socios, dicha dificultad está, también, presente y así, por ejemplo, aunque operan las mismas causas previstas en la LSC y en la LME, algunas requieren del acomodo necesario, precisamente, por la singularidad de las sociedades laborales. Nuestro estudio, como ha sido resaltado con anterioridad, se centra en el régimen propio de la LSLyP que regula, expresamente, como causa propia de separación del socio la pérdida de la calificación de la sociedad como laboral, habiendo quedado excluida ex lege para los socios trabajadores de la sociedad laboral el derecho de separación en caso de falta de distribución de dividendos (artículo 16.1 y 2 Ley 44/2015, respectivamente) y, asimismo, se abordan las causas propias de exclusión de los socios en las sociedades laborales con alusión a los efectos que, tanto la separación como la exclusión de socios, desencadenan en la esfera societaria.

Todos esos aspectos se consideran especialmente relevantes para el régimen y funcionamiento de las sociedades laborales que, además, pueden ocasionar una reestructuración subjetiva societaria que sea tan significativa como para acarrear la propia extinción de la sociedad como laboral. Así, la novedad del régimen jurídico previsto respecto de la separación y de la exclusión de socios y sus elementos configuradores propios constituyen las bases esenciales objeto del presente trabajo de investigación con remisión, como derecho supletorio, al régimen de la separación y de la exclusión de socios de la LSC (artículos 346 a 359 LSC), que no siempre resultará labor sencilla, ni adecuada a la especialidad laboral de la sociedad anónima o limitada de que se trate.

En la realización del estudio propuesto, no se desconoce la pretensión del legislador con la nueva regulación de la potenciación de las connotaciones propias de las sociedades laborales y como entidades societarias integrantes del modelo de economía social, como reconoce expresamente la Exposición de Motivos de la LSLyP (tanto por sus fines como por sus principios inspiradores), que justifican su regulación especial $\mathrm{y}$, en consonancia con ello, el régimen jurídico relativo al derecho de separación y de exclusión de socios en las sociedades laborales. Con todo, no puede afirmarse, conforme a la regulación actual, la autonomía tipológica de las sociedades laborales (Paniagua, 2015a; Paniagua, 2015b; Paniagua, 2004) y, por ello, la doctrina sigue dividida en torno a su verdadera caracterización: nuevo tipo de la economía social, sociedad mercantil de capital especial, sin faltar argumentaciones eclécticas o híbridas que sitúan a las sociedades laborales a medio camino entre las sociedades de capital especial y la sociedad de economía social 
(Paniagua, 2015: 738-739, "Las sociedades laborales..."), a falta de un deseable tipo social ad hoc para las sociedades laborales (Paniagua, 2015a; Diez Acimas, 2016).

Dicha indefinición tendrá su reflejo, también, en lo que constituye nuestro objeto de estudio ya que el interés colectivo de sus integrantes, el interés general, económico o social, o ambos intereses en las sociedades laborales como entidades de la economía social les repercute en la medida que, como ha afirmado la doctrina, en las sociedades laborales debe primar el interés de las personas y el interés social sobre el capital junto con los principios de gestión transparente, autónoma, democrática y participativa, en donde resulta relevante, asimismo, las personas para la toma de decisiones sociales y su aportación de trabajo a la sociedad más que su participación al capital social (Saldaña, 2016). Siendo el trabajo su objeto esencial, las sociedades laborales responden a una finalidad esencial de promoción social como vehículo favorecedor del autoempleo colectivo (Ciruela-Lorenzo, Cuadrado y Plaza, 2016).

En todo caso, las sociedades laborales se presentan en el contexto actual como entidades de naturaleza mercantil capitalista (sociedades mercantiles por la forma artículo 2 LSC-) pero administrativamente laborales (artículo 2 LSLyP) y marcado carácter social: entidades englobadas dentro del ámbito de la economía social, de conformidad con la Ley 5/2011, de 29 de mayo, de Economía Social (Mateo, 2016). Baste recordar, respecto de ésta última consideración, que la misma LSLyP da respuesta al mandato de la Disposición Adicional Séptima de la Ley 5/2011, de 29 de marzo de Economía Social, que ordenaba al Gobierno la revisión y actualización de la Ley de Sociedades Laborales (Ley 4/1997, de 24 de marzo de Sociedades Laborales). No obstante, grosso modo, puede afirmarse el carácter continuista de la nueva regulación para las sociedades laborales sin perjuicio de mejoras esenciales en su régimen societario (García, 2017), como la relativa al régimen de la separación y exclusión de socios ${ }^{3}$.

Con tales consideraciones previas, y de forma sintética, en las páginas que siguen se estudia el derecho de separación de los socios en las sociedades laborales previsto en el artículo 16.1 LSLyP. El derecho de separación en caso de falta de distribución de dividendos del artículo 348 bis LSC, conforme a la legislación propia para las sociedades laborales, artículo 16.2 LSLyP, se aborda en la medida

\footnotetext{
Debe destacarse, igualmente, la simplificación y reducción de trámites constitutivos con la integración de fórmulas electrónicas para su constitución, la mejora de la coordinación registral entre el registro administrativo de sociedades laborales y el registro mercantil (artículo 4 LSLyP) y, fundamentalmente, la protección para los socios trabajadores fomentando su participación e implicación en la sociedad laboral, así como la integración en la misma a los trabajadores no socios de la sociedad. Todo ello queda patente, también, con la regulación que se hace, por primera vez, de la posibilidad de adquirir la sociedad laboral sus propias acciones o participaciones sociales - siquiera sea temporalmente- y la facilitación de asistencia financiera para la adquisición de sus propias acciones o participaciones a los trabajadores de la sociedad con contrato a tiempo indefinido, que no sean socios de la sociedad laboral (artículo 12 Ley 44/2015). En el mismo sentido, la LSLyP incluye ciertas especialidades, fundamentalmente, en materia de transmisión de la posición de socio -derivadas, en lo esencial, de la propia condición como socio trabajador o no trabajador de la sociedad o bien, en su caso, de la condición de trabajador de la misma, y como novedad regula, también, la posibilidad de que los estatutos sociales señalen los criterios y sistemas de determinación previa del valor de las acciones o participaciones sociales para los supuestos de trasmisión o amortización, prevaleciendo lo acordado estatutariamente, así como la constitución de un fondo especial de reserva (artículo 14 LSLyP) y la concesión de determinados beneficios fiscales (artículo 17 Ley 44/2015), con la única condición de la calificación como laboral de la sociedad.
} 
que resultará aplicable a los socios no trabajadores de la sociedad laboral, cumplidos sus presupuestos. Asimismo, se analizan las peculiaridades para las sociedades laborales respecto de la exclusión de socios y los efectos que tanto el ejercicio del derecho de separación como la exclusión de socios producen a la sociedad laboral.

\section{El derecho de separación de los socios en las sociedades laborales: la descalificación de la sociedad}

La singularidad tipológica de la sociedad laboral justifica su propia causa específica que posibilita el derecho de separación. Así, el artículo 16.1 LSLyP configura como causa de separación a la pérdida de la calificación de la sociedad como laboral. Dicha pérdida puede obedecer en virtud de lo establecido en el artículo 15.1 LSLyP, que determina las causas legales de la pérdida de la calificación como laboral de la sociedad o, bien, en virtud del correspondiente acuerdo de la junta general que, adoptado con los requisitos y las mayorías establecidas para la modificación de estatutos, acuerde la referida pérdida de la condición de sociedad laboral -artículo 15.4 LSLyP-. Además, dependiendo de la causa de que se trate quedarán condicionados los socios legitimados, en su caso, para el ejercicio del derecho de separación -artículo 16.1 Ley 44/2015. Todos esos aspectos son analizados, a continuación, centrando la atención en la pérdida de la calificación de la sociedad como laboral por constituir su causa específica que justifica el ejercicio del derecho de separación.

Así, en las sociedades laborales, junto al régimen general para las sociedades capitalistas en donde quedan reguladas las causas legales (y, en su caso, estatutarias) que configuran el posible ejercicio por parte del socio del derecho de separación (artículos 346 y 347 LSC) ${ }^{4}$, el artículo 16.1 LSLyP introduce su causa especial (en realidad, el artículo 16 LSLyP introduce dos especialidades, en el ámbito de las causas de separación, a tenor el artículo 16.2 LSLyP). Conforme a ello, puede afirmarse que, en las sociedades laborales es causa legal que permite el ejercicio del derecho de separación de sus socios la pérdida de la calificación como laboral de la sociedad (artículo 16.1 Ley 44/2015). No obstante, no es eso lo que

4 Conforme a ello, el artículo 346 LSC regula las causas legales de separación, señalando que "1. Los socios que no hubieran votado a favor del correspondiente acuerdo, incluidos los socios sin voto, tendrán derecho a separarse de la sociedad de capital en los casos siguientes: a) Sustitución o modificación sustancial del objeto social. b) Prórroga de la sociedad. c) Reactivación de la sociedad. d) Creación modificación o extinción anticipada de la obligación de realizar prestaciones accesorias, salvo disposición contraria de los estatutos. 2. En las sociedades de responsabilidad limitada tendrán, además, derecho a separarse de la sociedad los socios que no hubieran votado a favor del acuerdo de modificación del régimen de transmisión de las participaciones sociales. 3. En los casos de transformación de la sociedad y de traslado de domicilio al extranjero los socios tendrán derecho de separación en los términos establecidos en la Ley 3/2009, de 3 de abril, sobre modificaciones estructurales de las sociedades mercantiles". Por su parte, el artículo 347 LSC, respecto de las causas estatutarias de separación regula que "1. Los estatutos podrán establecer otras causas de separación distintas a las previstas en presente ley. En este caso determinarán el modo en que deberá acreditarse la existencia de la causa, la forma de ejercitar el derecho de separación y el plazo de su ejercicio. 2. Para la incorporación a los estatutos, la modificación o la supresión de estas causas de separación será necesario el consentimiento de todos los socios". La LME también prevé causas legales de separación aplicables a las sociedades laborales que, igual que las previstas en la LSC, exigen su acomodo a la singularidad tipológica de las sociedades laborales. 
literalmente dice el legislador aunque, por nuestra parte, no podamos entenderlo de otra manera.

El artículo 16.1 LSLyP reza lo que sigue: "La pérdida de la calificación de la sociedad como laboral podrá ser causa legal de separación por parte del socio...". La literalidad de la norma podría llevar a entender, fácilmente, que los estatutos sociales sean los que, en su caso, puedan establecer tal posibilidad de que la pérdida de la calificación como laboral de la sociedad habilite el derecho de separación (García Valdecasas, 2015). Sí esa fuera la interpretación correcta de la norma y el sentido querido por el legislador, la pérdida de la calificación como laboral de la sociedad sería causa estatutaria de separación cuya incorporación, modificación o supresión exigiría el consentimiento de todos los socios (artículo 347.2 LSC) y no causa legal de separación. Sin embargo, no es ese el sentido que deba darse a la norma. Por nuestra parte, el legislador ha configurado a la pérdida de la calificación como laboral de la sociedad como "causa legal de separación por parte del socio" ya que, de un lado, así se recoge expresamente en el precepto de referencia, como se ha visto, y, de otro lado, el verbo "podrá", dice la norma "podrá ser causa de separación..." que es el que puede inducir a una interpretación errónea del artículo 16.1 LSLyP, estará referido al posible ejercicio por parte del socio del derecho de separación estando, eso sí, legitimado activamente para ello.

Al respecto, puede recordarse que, el derecho de separación del socio posibilita la resolución parcial del vínculo contractual con la sociedad y se configura en la legislación societaria como un derecho subjetivo del socio, ya que su ejercicio dependerá de su propia voluntad una vez manifestadas las causas legales o, en su caso, estatutarias debidamente configuradas (Fernández de Córdoba, 2013). En éste caso, como ha quedado expuesto, causa legal de separación. Con carácter general, existiendo modificaciones o variaciones respecto de la configuración jurídica de la posición de socio se le reconoce al socio el derecho de separación que además, en ocasiones, permite poner fin a situaciones de conflicto sin que su ejercicio conlleve la liquidación de la sociedad. Para la sociedad, por su parte, el ejercicio del derecho de separación supondrá la obligación de restituir el valor de las acciones o de las participaciones sociales lo que conllevará su amortización o su adquisición por la sociedad (Alfonso Sánchez, 2016), lo que difiere, como se verá, del régimen propio para las sociedades laborales, artículo 16.3 LSLyP.

\subsection{Causas forzosas y causa voluntaria de pérdida de la calificación como laboral de la sociedad}

La pérdida de la calificación de la sociedad como laboral se puede producir en virtud de las causas legales previstas por el legislador o bien, en su caso, en virtud del correspondiente acuerdo de descalificación acordado por la junta general, adoptado con los requisitos y las mayorías establecidas para la modificación de los estatutos (artículo 15.4 Ley 44/2015). De esa manera, se pueden diferenciar entre causas forzosas y causa voluntaria de descalificación de la sociedad, lo que incide sobre los posibles socios que, en su caso, podrán ejercitar el derecho de separación (Andreu Martí, 2013; Lázaro Sánchez, 2017). 


\subsubsection{Causas forzosas de pérdida de la calificación como laboral de la sociedad}

En el ámbito de las causas forzosas que originan la pérdida de la calificación de la sociedad como laboral, no existe diferencia entre el régimen previsto en la vigente LSLyP y el correspondiente establecido en la derogada Ley de Sociedades Laborales (artículo 16, de la Ley 4/1997, de 24 de marzo). Se mantienen las mismas causas legales que originaban y, que por tanto, originan la pérdida de la referida calificación. Dichas causas están previstas en el artículo 15.1 LSLyP y son las que se reproducen a continuación: la superación de los límites establecidos en el artículo 1, sin perjuicio de las excepciones previstas en el mismo y la falta de dotación, la dotación insuficiente o la aplicación indebida de la reserva especial. Dichas causas legales encuentran su justificación en el incumplimiento de los requisitos tipológicos de las sociedades laborales o en el incumplimiento de la disciplina contable y financiera de la sociedad laboral (Lázaro Sánchez, 2017).

En tales casos, verificada la existencia de cualquiera de sus causas legales cuando no se haya comunicado (según lo establecido en el artículo 1.3 LSLyP) o, en el caso de comunicación, cuando hayan transcurrido los plazos de adaptación para el cumplimiento de los requisitos exigidos para la calificación de la sociedad como laboral (previstos en el artículo 1.3 LSLyP) y, tras la instrucción del oportuno expediente, procederá la descalificación de la sociedad como sociedad laboral y se ordenará su baja en el Registro administrativo de Sociedades Laborales procediendo, con posterioridad, remisión de certificación de la resolución y de la baja al Registro Mercantil para que obedezca nota marginal en la hoja abierta a la sociedad (artículo 15.2 Ley 44/2015).

Dichas causas forzosas desencadenantes de la pérdida de la calificación como laboral de la sociedad conforme a la jurisprudencia decantada uniformemente, han de ser consideradas con carácter restrictivo (Neila Neila, 1998: 276), sin que se pueda recurrir a la analogía para considerar otras posibles causas de pérdida de la calificación al derivarse, además, la pérdida de determinados derechos. Así, de un lado, una vez descalificada la sociedad procederá la pérdida y el reintegro de los beneficios y ayudas públicas adquiridas como consecuencia de su condición de sociedad laboral, desde el momento en el que la sociedad haya incurrido en cualesquiera de las causas que han originado la pérdida de la referida calificación y que abren, de otro lado, la vía para el posible ejercicio de derecho de separación a cualesquiera de los socios de la misma.

Conforme a ello, el derecho de separación no aflora automáticamente como consecuencia de la existencia de alguna o de algunas de sus causas legales, ya que será necesaria la constatación de las mismas en virtud del correspondiente proceso administrativo de descalificación que será el que determine la existencia y, en su

5 El artículo 15.2 LSLyP regula que "Verificada la existencia de causa legal de pérdida de la calificación, cuando no se haya comunicado conforme al apartado 3 del artículo 1, o en el caso de comunicación cuando hayan transcurrido los plazos de adaptación previstos en dicho artículo, el Ministerio de Empleo y Seguridad Social o el órgano competente de la Comunidad Autónoma correspondiente, tras la instrucción del oportuno expediente, descalificará a la sociedad como "Sociedad Laboral», ordenando su baja en el Registro de Sociedades Laborales. Efectuado el correspondiente asiento, se remitirá certificación de la resolución y de la baja al Registro Mercantil para la práctica de nota marginal en la hoja abierta a la sociedad". 
caso, persistencia de la causa, o causas legales, desencadenante de la descalificación. De esa manera, el legislador en supuestos de transgresión sobrevenida de los límites establecidos en los apartados a) y b) del artículo 1.2 LSLyP ha regulado que "...la sociedad estará obligada a acomodar a la ley la situación de sus socios, en el plazo de dieciocho meses a contar desde el primer incumplimiento". Al respecto, ha sido ampliado dicho plazo frente al correspondiente en la Ley 4/1997, que era de doce meses. Igual ocurre respecto de la superación de la exigencia prevista en el apartado c) del artículo 1.2 LSLyP, relativa al número de horas-año trabajadas por los trabajadores, habiéndose concediendo un plazo de doce meses para acomodarse a tal requerimiento (y pudiendo concederse hasta un máximo de dos prórrogas si se acredita en cada solicitud de prórroga que se está avanzando en el proceso de adaptación a los límites previstos para el cumplimiento de los elementos conceptuales de la LSLyP).

Todo ello puede traducirse en una mayor flexibilización del marco de contratación de los trabajadores no socios de la sociedad laboral y de los plazos de adaptación a la LSLyP cuando han sido trasgredidos los límites de capital y de contratación de trabajadores no socios, en aras de la persistencia de la condición de laboral de la sociedad (Mateo Hernández, 2016). Ello explica el mandato del legislador previsto en el artículo 1.3 LSLyP cuando, en relación al incumplimiento de los requisitos que han de concurrir en la sociedad laboral, regula que "la superación de los límites y de las circunstancias que originan dicha situación, así como su adaptación posterior a la ley, deberán ser comunicados al Registro de Sociedades Laborales, en el plazo de un mes desde que se produzcan, a los efectos previstos en el apartado 2 del artículo 15 de la presente ley".

De esa forma, el legislador posibilita, con la comunicación al Registro de Sociedades Laborales, la regularización de la sociedad para evitar la pérdida de la calificación en los supuestos de la superación de los límites legales conceptuales de la sociedad laboral (artículo 1.2 LSLyP) ${ }^{6}$. En otro caso, como ha sido anticipado, verificada la existencia de causa legal de pérdida de la calificación, la ausencia de la referida comunicación o, habiendo sido comunicada, el transcurso de los plazos que posibilitan la adecuación a la exigencia de la LSLyP, se abre la vía del expediente relativo a la descalificación de la sociedad, artículo 15.2 LSLyP. En tanto se promulgue el nuevo Real Decreto regulador del Registro Administrativo de Sociedades Laborales (Disposición Final Cuarta LSLyP), el procedimiento para la pérdida de la calificación de la condición laboral de la sociedad y su ajuste a lo que el mismo dictamine, habrá de tomarse en consideración las disposiciones compatibles con el Real Decreto 2114/1998, de 2 de octubre, sobre el Reglamento Administrativo de Sociedades Laborales (Lázaro Sánchez, 2017).

6 En concreto, en el supuesto de que la sociedad se constituya con dos socios trabajadores con contrato a tiempo indefinido, en la que el capital y los derechos de voto estarán distribuidos al cincuenta por ciento, tienen la obligación de ajustarse al límite previsto en el artículo 1.2, b LSLyP en el plazo máximo de 36 meses. Cuando se transgredan de forma sobrevenida los límites previstos en los apartados a) y b) del artículo 1.2 LSLyP, la sociedad estará obligada a acomodar su situación a lo establecido en la Ley en el plazo de 18 meses a contar desde el primer incumplimiento. Cuando los límites que se superan sean los previstos en el apartado c) el artículo 1.2 LSLyP, el plazo máximo para ajustarse a lo establecido en la Ley es de doce meses, si bien el órgano del que dependa el Registro de Sociedades Laborales podrá conceder hasta dos prórrogas, por plazo máximo de doce meses cada una, cuando se acredite en cada solicitud de prórroga que se está avanzando en el proceso de adaptación a los límites previstos en la LSLyP. 
Por el contrario, en los supuestos en los que la causa legal de descalificación esté conectada con la falta de dotación, la dotación insuficiente o la aplicación indebida de la reserva especial (artículo 15.1.2 ${ }^{\mathrm{a}}$ LSLyP), el legislador no concede ningún plazo que posibilite la adecuación de la sociedad a las exigencias de su carácter laboral, por lo que tendrá cabida expediente administrativo para la descalificación de la sociedad como laboral, que habilitará el posible ejercicio del derecho de separación a todos los socios de la sociedad con independencia de su condición (es decir, sean o no sean trabajadores de la sociedad: socios trabajadores con carácter indefinido -tiempo completo o parcial- y socios no trabajadores).

\subsubsection{Causa voluntaria de pérdida de la calificación como laboral de la sociedad}

Por su parte, cuando la descalificación es voluntaria, es decir cuando la perdida de la sociedad de su calificación como laboral se produce por acuerdo de la junta general adoptado con los requisitos y las mayorías establecidas para la modificación de estatutos sociales (artículo 15.4 LSLyP), la sociedad cumple tanto con los requisitos tipológicos propios de la sociedad laboral como los propios de su disciplina contable y financiera y es el acuerdo soberano de la junta general el que decide poner fin a la calificación de la sociedad como laboral. Aquí, también tiene cabida el derecho de separación, pero sólo respecto de los socios que no votaron a favor del acuerdo de descalificación (como se señaló anteriormente, con independencia, por tanto, de su condición como socio trabajador o no trabajador de la sociedad).

En tal supuesto, será preciso diferenciar dos acuerdos diferentes. Por un lado, el relativo a la descalificación de la sociedad y, por otro lado, el relativo a la modificación de los cambios necesarios en los estatutos sociales ya que, aunque ambos acuerdos se encuentren relacionados, quedan sometidos a sus requisitos propios y poseen efectos jurídicos distintos (Lázaro Sánchez, 2017) ${ }^{7}$. Así, dada la transcendencia del acuerdo de descalificación, en el orden del día de la junta general de que se trate deberá figurar expresamente la solicitud de renuncia a la calificación de la sociedad de su condición de laboral, sin que sea posible una mención sólo a la modificación de estatutos sociales (Paniagua, 2015a) ${ }^{8}$.

El acuerdo de la junta general relativo a la descalificación de la sociedad exige dar cumplimiento a los requisitos respecto del ejercicio del derecho de separación. Al respecto, de conformidad con el artículo 348 LSC, el ejercicio del derecho de separación exige publicidad del acuerdo que ampara su ejercicio, es decir, del correspondiente acuerdo de descalificación. En tal sentido, será necesaria la

\footnotetext{
La protección del socio disconforme con la modificación de los estatutos encuentra su cauce legal en el régimen general para las sociedades de capital y, dependiendo de la modificación de que se trate, puede exigir el consentimiento individual del socio afectado, el derecho de separación, etc. Cuando se trata del acuerdo de descalificación de la sociedad como laboral el cauce legal supone el posible ejercicio del derecho de separación de los socios que no votaron a favor del acuerdo. Ambos acuerdos están relacionados ya que el acuerdo de descalificación requiere, asimismo, el acuerdo de modificación de los estatutos para adaptarse a la Ley de Sociedades de Capital y ambos acuerdos exigen constancia en el Registro Mercantil, que deberá ser simultánea al serlo también en el supuesto del otorgamiento de la calificación de laboral a una sociedad ya inscrita.

8 Expresamente, la RDGRN de 2 de junio de 2003, Fj $2^{\circ}$.
} 
publicación del acuerdo de descalificación en el BORME o bien, en su caso, en sustitución de la referida publicación, los administradores de la sociedad laboral podrán comunicar por escrito el acuerdo de descalificación a cada uno de los socios que no han votado a favor del acuerdo (artículo 348.1 LSC). Ello, desde luego, es posible en las sociedades laborales en virtud de la exigencia de que su capital social está dividido en acciones nominativas o, en su caso, en participaciones sociales (artículo 5.1 LSLyP en relación con el artículo 348.1 LSC).

Los socios que desean separarse deben comunicarlo por escrito a la sociedad (artículo 16.4 LSLyP en relación con el artículo 348.2 LSC), y cuentan para ello con el plazo de mes "...desde la publicación del acuerdo o desde la recepción de la comunicación" (artículo 348.2 LSC).

Ahora bien, al igual que se veía en los supuestos anteriores de descalificación forzosa, será precisa, también, la resolución administrativa de descalificación que operará a instancia de la propia sociedad por tratarse de causa voluntaria de pérdida de la calificación. Ello exigirá, una vez sea dictada resolución administrativa de descalificación y extendido el correspondiente asiento de baja de la sociedad laboral en el Registro Administrativo, certificación por parte de la correspondiente autoridad administrativa para su remisión a la propia sociedad a efectos de su constancia en el Registro Mercantil. No opera, a diferencia de los supuestos anteriores de descalificación forzosa, remisión directa de la certificación al Registro Mercantil (Lázaro Sánchez, 2017) 9

\subsection{Ejercicio del derecho de separación: legitimación activa}

Respecto de la legitimación activa y en relación a las causas forzosas de descalificación, se puede afirmar que la calificación como laboral se erige como esencial al vínculo del socio con la sociedad de la que forma parte, ya que su descalificación posibilita, por tal motivo, el ejercicio del derecho de separación a cualquiera de los socios de la sociedad y no sólo a los socios trabajadores de la misma, sobre los que se asienta la sociedad laboral como uno de sus pilares esenciales. Los socios no trabajadores también pueden separarse cuando se produce la descalificación de la sociedad. Lo cual, como elemento potenciador de la singularidad tipológica de la sociedad laboral resulta acertado aunque las consecuencias jurídicas que puede provocar su ejercicio por todos los socios frente a la sociedad puedan hacer peligrar su propia existencia y provocar, incluso, la disolución societaria (Lázaro Sánchez, 2017).

Cuando la descalificación es voluntaria (se origina por acuerdo de la Junta General y son los propios socios los que configuran el acuerdo mayoritario de pérdida de la calificación), el derecho de separación sólo podrá ser ejercitado por los socios que no votaron a favor del referido acuerdo. Lo que incluye a los socios que no han concurrido a la junta (por sí mismo o por medio de representante), a los que han concurrido pero su voto ha sido contrario al acuerdo adoptado de descalificación, se han abstenido o votado en blanco (Andreu Martí, 2013). Ello

9 La sociedad laboral formulará su solicitud acompañada de la correspondiente documentación acreditativa del acuerdo (en espera del correspondiente desarrollo reglamentario por contraste selectivo y adaptado a lo dispuesto en el artículo $2,2^{\circ}$ y $3^{\circ}$ LSLyP), que requiere “...copia autorizada de la escritura de elevación a público del acuerdo de la junta general favorable a la descalificación...". 
posibilitará la permanencia de la sociedad de capital -bien sea anónima o limitadacon los socios que, en su caso, no han ejercitado el derecho de separación y con los socios que tienen vetado, por dicha causa -por haber servido su voto para conformar el acuerdo social de descalificación de la sociedad-, el referido derecho de separación.

Todo ello será así, salvado el supuesto que posibilita que vía estatutos sociales se establezca como causa de disolución societaria la pérdida de la condición de laboral de la sociedad de que se trate (artículo 15.6 LSLyP, en los mismos términos del artículo 17.2 de la derogada Ley 4/1997, de 24 de marzo, de Sociedades Laborales), lo que reafirma la consideración anterior de que la calificación como laboral se erige como esencial a su categoría hasta el punto de poder constituir una causa de disolución societaria. En tal caso, se trataría de una causa estatutaria de disolución societaria que abrirá el correspondiente procedimiento disolutivo de la sociedad, pero si la perdida de la calificación de la sociedad de su condición como laboral no es causa estatutaria de disolución, la descalificación no impide la continuación de la actividad que constituya del objeto de la sociedad. Seguirá siendo una sociedad capitalista mercantil.

\subsection{Sociedad laboral versus sociedad capitalista mercantil por virtud de la descalificación}

La descalificación de la sociedad da paso al posible ejercicio del derecho de separación a los socios legitimados para ello y hace que obedezca, también, la baja de la sociedad en el Registro Administrativo de Sociedades Laborales, habiendo obedecido, asimismo, la anotación en la página abierta a la sociedad en el Registro Mercantil, de la perdida de la condición de sociedad laboral, la sociedad anónima $\mathrm{o}$, en su caso, de responsabilidad limitada. Si bien, mantiene su personalidad jurídica y la validez de su actuación realizada. No obstante, sus efectos se desencadenan en la esfera propia de su condición laboral y de ahí que proceda la pérdida y el reintegro de los beneficios y ayudas públicas (artículo 15.5 LSLyP) y en la propia mercantil. Dicha sociedad dejará, en adelante, de estar sometida a la LSLyP en cumplimiento del artículo 1.1 LSLyP, quedando reguladas, en exclusiva, por el régimen general del Texto Refundido de la Ley de Sociedades de Capital. Desaparece, en consecuencia, la dualidad de acciones o de participaciones de la clase laboral y de la clase general y, sus estatutos, también, tendrán que adaptarse a la Ley de Sociedades de Capital, no pudiendo constar la condición de laboral en la denominación social.

El ejercicio del derecho de separación, consecuencia de la descalificación operada, supondrá para la sociedad atender al cumplimiento del plazo máximo de cuatro meses -desde la recepción del escrito del socio comunicando tal ejerciciopara que el socio separado pueda obtener en el domicilio social el valor de sus acciones o participaciones -artículo 16.4 LSLyP-. Lo que enlaza con otros aspectos relevantes, como el de la valoración de las acciones o de las participaciones sociales y el de la situación económica en la que se encuentra la sociedad para poder atender al cumplimiento o ejecución del derecho de separación. No puede olvidarse, la posibilidad de que la sociedad pueda seguir siendo sociedad laboral, sobre todo en el supuesto del ejercicio del derecho de separación por todos los 
socios que, en su caso, pueden ejercerlo: todos los socios en los supuestos de descalificación forzosa de la sociedad laboral y todos los socios que no votaron a favor del acuerdo de descalificación en el supuesto de la descalificación voluntaria (Lázaro Sánchez, 2017).

\section{El derecho de separación de los socios no trabajadores de las sociedades laborales en caso de falta de distribución de dividendos}

Junto a la descalificación de la condición de laboral de la sociedad, la falta de distribución de dividendos se erige, también, como causa que justifica el ejercicio del derecho de separación, en éste caso, de los socios no trabajadores de las sociedades laborales. En efecto, el artículo 16. 2 LSLyP sólo excluye a los socios trabajadores de la sociedad laboral del referido derecho de separación en caso de falta de distribución de dividendos por lo que para aquellos, tal derecho de separación rige en todos sus términos. Como se sabe, desde el pasado 1 de enero de 2017 está vigente el nuevo derecho de separación en caso de falta de distribución de dividendos, previsto en el artículo 348 bis LSC, y cuyo ámbito de aplicación subjetivo está referido a las sociedades capitalistas no cotizadas, cumplidos sus presupuestos, ampliamente debatidos $\mathrm{y}$, en muchas ocasiones, puestos en duda (recientemente, Pulgar Ezquerra, 2017).

Las sociedades laborales como sociedades capitalistas no cotizadas son destinatarias del ámbito subjetivo de aplicación del artículo 348 bis LSC. Como ha sido anticipado, las sociedades laborales, en virtud de la Disposición Final Tercera LSLyP, atraen como derecho supletorio el régimen jurídico de las sociedades capitalistas (anónimas o limitadas, según su forma jurídica) salvado su propio régimen jurídico que, en éste caso, sólo ha excluido de su aplicación a los socios trabajadores de la sociedad laboral. Así, los socios trabajadores de las sociedades laborales carecen del derecho de separación en caso de falta de distribución de dividendos en virtud de lo establecido en su Ley especial -artículo 16.2 Ley 44/2015- frente al régimen general del Texto Refundido de la Ley de Sociedades de Capital -artículo 348 bis LSC-, que resulta aplicable a todas las sociedades capitalistas no cotizadas.

\subsection{Socios de la sociedad laboral y fundamento de la aplicación del artículo 348 bis LSC a los socios no trabajadores}

En la sociedad laboral pueden convivir, dentro de su marco legal, socios trabajadores y socios no trabajadores junto a trabajadores no socios de las sociedad (en función de ello, aquellos socios serán titulares de acciones o de participaciones sociales de la clase laboral o general, respectivamente). Sobre los socios trabajadores descansa la existencia misma de la sociedad laboral ya que, de conformidad con el artículo 1.2 LSLyP, al menos la mayoría del capital social estará en manos de los socios trabajadores, que prestan sus servicios en la sociedad de forma personal y directa y que, por lo tanto, están vinculados a la sociedad en una doble vertiente: como socios y como trabajadores con relación laboral de carácter indefinido con la sociedad. Podría decirse que se trata de una especie de 
híbrido entre la figura del trabajador por cuenta ajena y el socio industrial, siendo compatible el vínculo trabajador/socio en la caracterización esencial de la sociedad laboral (Cavas Martínez y Selma Peñalva, 2011; Paniagua, 2015a).

Sobre todos los socios, además, y salvo las excepciones previstas en la LSLlyP (artículo 1.2, apartado b LSLyP), recaen los límites de tenencia máxima de capital social, no pudiendo representar más de la tercera parte del capital social. Y, finalmente, el número de horas-año trabajadas por los trabajadores por tiempo indefinido que no sean socios, no podrá ser superior al cuarenta y nueve por ciento del cómputo global de horas-año trabajadas en la sociedad laboral por el conjunto de los socios trabajadores (artículo 1.2 LSLyP).

Todos esos requisitos, que han estar presentes en la sociedad anónima o en la sociedad de responsabilidad limitada para que pueda obtener el calificación de sociedad laboral (artículo 1.2 LSLyP), inciden en lo que consideramos el fundamento de la aplicación del artículo 348 bis LSC a los socios no trabajadores de la sociedad laboral. En efecto, al representar los socios trabajadores la mayoría de capital social no encarnan el ámbito tuitivo que inspiró la introducción en nuestro ordenamiento jurídico del artículo 348 bis LSC: defensa de la minoría societaria en las sociedades no cotizadas. Los socios minoritarios de las sociedades capitalistas no cotizadas veían como su participación en los beneficios sociales como contraprestación a su participación en la sociedad se frustraba sistemáticamente cuando los socios mayoritarios votaban en contra de la distribución de dividendos sin que, por otro lado, les resultara sencilla la enajenación de su participación en la sociedad al carecer de un mercado organizado que lo facilitase. Grosso modo, dichas circunstancias justificación el reconocimiento legal del derecho de separación en caso de falta de distribución de dividendos para las sociedades capitalista no cotizadas (Pulgar Ezquerra, 2017; Cañabate, 2017).

En el ámbito propio de las sociedades laborales dicha justificación no encuentra el mismo acomodo. Así, los socios minoritarios de capital en las sociedades laborales son los socios no trabajadores para los que si tiene cabida el régimen jurídico previsto en el artículo 348 bis LSC. En tal sentido, resulta acorde con la finalidad de la norma excluir a los socios trabajadores del ejercicio del derecho de separación en caso de falta de distribución de dividendos y posibilitar el mismo derecho para los socios no trabajadores de la sociedad laboral. Ambos son socios pero sometidos a distinto régimen jurídico derivado de su estatuto propio dentro de la sociedad laboral (Andreu Martí, 2013).

Ello, además, puede entenderse adecuado a las propias singularidades de las sociedades laborales que justifican su existencia como sociedad especial y entidad englobada en el ámbito de la economía social (Andreu Martí, 2013). Como afirma la doctrina, la principal razón de ser de las sociedades laborales es la creación de empleo y el estímulo a la puesta en marcha de proyectos empresariales por parte de los propios trabajadores (Cavas Martínez y Selma Penalva, 2011). El socio trabajador que, como exige el artículo 1.2,a) LSLyP presta en la sociedad "servicios retribuidos de forma personal y directa, en virtud de una relación laboral por tiempo indefinido" dista mucho del perfil del socio inversor -más pendiente de la rentabilidad por su participación en la sociedad que de cualesquiera otras circunstancias: con carácter general, acumulación de reservas, 
autofinanciación o, expansión de la sociedad y, con carácter particular, como fin social y de interés general en el ámbito de la economía social, la creación y/o el mantenimiento de empleo estable y digno, la participación de los trabajadores en la empresa y el control por parte de éstos de la empresa (Paniagua, 2015a; Paniagua, 2015b). Además, y abundando, coincide en las sociedades laborales la facilitación del acceso a la condición de socio trabajador de los trabajadores de la sociedad con contrato indefinido, como nota distintiva de su conformación y que ha sido un aspecto potenciado con la nueva regulación de las sociedades laborales.

Por esas razones, aunque los socios no trabajadores de una sociedad de responsabilidad limitada laboral, por aplicación supletoria del artículo 188.1 LSC, pudieran gozar de la mayoría de derecho de voto (aunque no posean la mayoría de capital social, por aplicación del artículo 1.2,a LSLyP), no parece muy adecuado a su perfil la negativa al reparto de dividendos frente a la mayoría de capital social (propiedad de los socios trabajadores, artículo 1.2,a LSLyP) reacios, posiblemente, a ese mismo reparto. Además, habiendo votado aquellos en contra del reparto de dividendos carecerían del derecho de separación amparado en el artículo 348.1 bis LSC, por incumplimiento de sus presupuestos ("...socio que hubiera votado a favor de la distribución de dividendos...de, al menos, un tercio de los beneficios propios de la explotación del objeto social...").

No obstante lo afirmado, no puede considerarse que la ausencia de reparto de dividendos sea una nota presente en las sociedades laborales. El derecho a participar en el reparto de las ganancias sociales se concibe como un derecho mínimo de los socios -artículo 93 LSC-, también, por lo tanto, de todos los socios de las sociedades laborales. Dicho derecho tiene su reconocimiento en los términos establecidos en la normativa legal y salvo los casos en ella previstos, pero se trata, también, de un derecho abstracto necesitado de concreción. Es decir, será necesario el acuerdo adoptado por la junta general -artículo 169,a) LSC- a partir de la existencia de beneficios sociales repartibles -artículo 273 LSC-. Sólo de esa manera, el derecho abstracto a la participación en las ganancias sociales se concreta en un derecho de crédito de los socios frente a la sociedad, en virtud de ese dividendo acordado, que puede ser exigido por los socios frente a la sociedad (Campuzano, 2011; Pulgar Ezquerra, 2017).

Conforme a ello, ni en el ámbito general de las sociedades capitalistas ni en el particular de las sociedades capitalistas laborales, si bien en éstas de forma más acusada por su condición de entidad integrada en el ámbito de la economía social (Paniagua, 2015a), está reconocido derecho alguno a un reparto obligatorio de dividendos, aunque los efectos que el ejercicio del derecho de separación en caso de falta de distribución de dividendos pueda ocasionar a la sociedad han llevado, a algún sector de la doctrina, a plantearlo (Rodríguez Ruiz de Villa, 2012). Los empresarios de la economía social no persiguen maximizar, de facto o como hipótesis, una inversión de capital, sino atender tanto las necesidades de sus miembros, como fines sociales y de interés general internalizados en su estatuto jurídico (Paniagua 2015a: 201).

Por el contrario, lo que el legislador ha reconocido para supuestos de ausencia de reparto de dividendos ha sido un nuevo derecho de separación, cumplidos los requisitos legales establecidos en el artículo 348 bis LSC que, en atención a la singularidad de la sociedad laboral, ha sido vetado para los socios trabajadores por 
esa misma causa y aun cumpliendo los requisitos exigidos para ello. El reparto de dividendos se presenta como elemento secundario para los socios trabajadores de la sociedad laboral al carecer de derecho de separación por tal motivo. Ello conecta con la necesidad advertida para las sociedades laborales de arbitrar medidas que eviten el abono encubierto de beneficios sociales entre los socios trabajadores, lo que requiere que la cuantía de los salarios que se les abona no exceda del valor correspondiente a la prestación laboral que realizada (Paniagua, 2015a).

Así, la participación en el reparto de las ganancias sociales, en los términos anticipados, forma parte del estatuto del socio trabajador si bien la ausencia del derecho de separación por falta de reparto de dividendos le impedirá la obtención del valor de sus acciones o participaciones, artículo 16.4 LSLyP, que podría servir para iniciar o tomar partida en otras iniciativas de autoempleo como sociedad laboral (incluso, en los términos posibilitados, temporalmente, del artículo 1.2.b LSLyP). En éste contexto, podría pensarse, además, en la posibilidad de impugnar acuerdos sociales abusivos de no reparto de dividendos, ex artículo 204.1 LSC, sobre todo cuando se trata de sociedades laborales en la que todos sus socios son socios trabajadores y carecen, por ello, del derecho de separación en caso de falta de reparto de dividendos (Pulgar Ezquerra, 2017; Cañabate, 2017).

\subsection{Naturaleza jurídica de la disposición}

Partiendo de las consideraciones anteriormente establecidas, conviene determinar la naturaleza jurídica del apartado 2 del artículo 16 Ley 44/2015 y, por lo tanto, su alcance respecto de los socios trabajadores y socios no trabajadores de la sociedad laboral.

Al respecto, parece clara la naturaleza imperativa del precepto. El legislador de forma expresa ha querido excluir a los socios trabajadores del supuesto amparado en el artículo 348 bis LSC lo que, como ha sido anticipado, resulta acertado por las peculiaridades de la sociedad laboral ${ }^{10}$. Una excepción más para las sociedades

10 El supuesto amparado en el artículo 16.2 LSLyP ve la luz estando suspendida la aplicación de lo dispuesto en el artículo 348 bis LS. Así, de haberse producido la derogación del artículo 348 bis LSC, como se había defendido por parte de algún sector de la doctrina por los efectos perjudiciales que para las sociedades capitalistas no cotizadas puede provocar su aplicación, en vez de su entrada en vigor como ha ocurrido el pasado 1 de enero de 2017, nos habríamos encontrado con la remisión a un precepto derogado y, por tanto, inaplicable materialmente a los socios no trabajadores de la sociedad laboral. La entrada en vigor del artículo

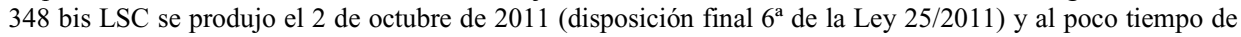
su entrada en vigor se produjo la suspensión de su aplicación. Dicha suspensión se introdujo a raíz del Proyecto de Ley de simplificación de las obligaciones de información y documentación de fusiones y escisiones de sociedades de capital (procedente del Real Decreto-Ley 9/2012, de 16 de marzo), que adicionó en el artículo primero (modificación del Texto Refundido de la Ley de Sociedades de Capital, aprobado por el Real Decreto Legislativo 1/2010, de 2 de julio), apartado cuatro, una nueva disposición transitoria a la LSC, que estableció lo siguiente: "Se suspende, hasta el 31 de diciembre de 2014, la aplicación de lo dispuesto en el artículo 348 bis de esta Ley" (BOCG núm. A-8-8, de 31 de mayo de 2012). Así, por Ley 1/2012, de 22 de junio, de simplificación de las obligaciones de información y documentación de fusiones y escisiones de sociedades de capital (BOE núm. 150, de 23 de junio de 2012), se introduce la referida disposición transitoria a la LSC, que entró en vigor al día siguiente de su publicación en BOE (Disposición final tercera). Con posterioridad se produjo una ampliación del plazo de suspensión de su aplicación a través del Real DecretoLey 11/2014, de 5 de septiembre, de medidas urgentes en materia concursal (BOE núm. 217, de 6 de septiembre), suspendiendo hasta 31 de diciembre de 2016 la aplicación de lo dispuesto en el artículo 348 bis de la Ley de Sociedades de Capital (disposición final primera), y de conformidad con la Ley 9/2015, de 25 de mayo, de medidas urgentes en materia concursal (procedente del Real Decreto-Ley 11/2014), la disposición 
laborales respecto del régimen aplicable a las sociedades capitalistas (Paniagua, 2015a). Ello impide, asimismo, admitir como causa estatutaria para los socios no trabajadores la no aplicación del supuesto amparado en el artículo 348 bis LSC ${ }^{11}$. El nuevo régimen jurídico para las sociedades laborales fortalece, de esa forma, la condición laboral de la sociedad que podría peligrar por el ejercicio del derecho de separación en caso de falta de distribución de dividendos de los socios trabajadores que representan la mayoría del capital social frente a los socios no trabajadores.

Así, los socios no trabajadores de la sociedad laboral gozan del derecho de separación en caso de falta de distribución de dividendos, cumplidos sus presupuestos ex artículo 348 bis LSC ${ }^{12}$, ampliamente debatidos y puestos en duda respecto de las sociedades capitalistas no cotizadas (momento temporal para su

transitoria de la Ley de Sociedades de Capital, quedó redactada en esos mismos términos descritos, habiendo quedado suspendida la aplicación del artículo 348 bis LSC hasta 31 de diciembre de 2016.

11 La novedad del derecho de separación amparado en el artículo 348 bis LSCE y su propio periplo, junto a los perjuicios que su aplicación puede acarrear para la sociedad y las dudas que han suscitado los presupuestos que su aplicación exige, ha proporcionado una abundante doctrina mercantil, siendo mayoritaria la doctrina que afirma que no cabe posibilidad de suprimirlo ni de admitir su modificación vía estatutaria: Silva Sánchez, M. J. y Sambeat Sastre, J.M. (2012) Análisis y crítica del artículo 348 bis de la Ley de Sociedades Capital. Diario La Ley, $N^{o} 7825$, de 26 de marzo de 2012, p. 5 y Diario La Ley, $N^{o} 7844$, de 24 de abril de 2012, p. 23, en donde recogen la posiciones doctrinales de Brenes Cortés, Illescas, Juste Mencía, y de Uría, Menéndez e Iglesias Prada, que sostienen que la norma es de ius Cogens. Dicho carácter imperativo, también, es afirmado por Zarzalejos Todedano, I. (2015) Derecho de separación en caso de falta de distribución de dividendos. $L a$ Ley Mercantil, N ${ }^{\mathrm{o}}$ 16, pp. 1-5. García Sanz, A. (2012) Derecho de separación en caso de falta de distribución de dividendos. Revista de Derecho de Sociedades, No 38, pp. 62-63.Alonso Ledesma, C. (2013) La autonomía de la voluntad en la exclusión y separación de socios. Revista de Derecho Mercantil, No 287, pp. 99. Vázquez Lépinette, T. (2012) La separación por justa causa tras las recientes reformas legislativas. Revista de Derecho Mercantil, No 283, pp.190-191. Marina García-Tuñon, A. (2017) Los derechos al dividendo y de separación a la luz del art. 348 bis de la Ley de Sociedades de Capital: una revisión general. Revista de Derecho de Sociedades, $\mathrm{N}^{\circ}$ 49, p. 13. Por su parte, Alvarez Royo-Villanova, S. y Fernández del Pozo, L. (2017) Una propuesta de redacción alternativa del artículo 348 bis LSC. La Ley Mercantil, № 33, p.6, sostienen la posible derogación vía disposición estatutaria. También, Alfaro Aguila Real, J. (2011) Derecho de separación del socio en caso de sequía de dividendos: el nuevo artículo 348 bis de la Ley de Sociedades de Capital, $C / M / S$, Albiñana\&Suárex de Lezo, noviembre, pp.1-6. Alfaro, J. y Campins, A. (2014) Abuso de la mayoría en el reparto de dividendos y derecho de separación del socio en las sociedades de capital. En: García de Enterría. J.; Lorenzo Velázquez. Liber Amicorum a Juan Luis Iglesias Pradas, p. 84, en donde sostienen que el derecho de separación del artículo 348 bis LSC es un “...derecho inderogable (por la mayoría) pero renunciable (por los socios)". Pulgar Ezquerra, J. (2017) Reparto legal mínimo de dividendos: protección de socios y acreedores (solveny test). Revista de Derecho de Derecho Bancario y Bursátil, No 147, pp.147-149. Asimismo, a favor del carácter disponible del precepto González Castilla, F. (2012) Reformas en materia de separación y exclusión de socios. En: Rodríguez Artigas, F.; Farrando Miguel, I.; González Castilla, F. Las reformas de la Ley de Sociedades de Capital (Real Decreto-Ley 13/2010, Ley 2/2011, Ley 25/2011 y Real Decreto-ley 9/2012), pp. 262-263. No obstante, como sostienen Silva Sánchez, M. J. y Sambeat Sastre, J.M. (2012) Análisis y crítica del artículo 348 bis de la Ley de Sociedades Capital. Diario La Ley, $N^{o} 7825$, p. 5, y en Diario La Ley, N $\mathrm{N}^{\circ} 7844$, pp. 2-3, "el derecho de separación establecido en el artículo 348 bis de la LSC es una causa de separación legal y, por tanto, sometido a la disciplina del art. 346 LSC y no a la del art. 347 LSC, por lo que no le sería aplicable la posibilidad de su modificación o supresión por acuerdo unánime". También, Cáceres Carceles, C. (2012) El ejercicio de derecho de separación del socio en caso de no distribución de dividendos. Las reformas introducidas por el artículo 348 bis LSC. Derecho de los Negocios, $\mathrm{N}^{\mathrm{o}} 263-264$, p. 39.

12 El artículo 348 bis LSC regula: "1. A partir del quinto ejercicio a contar desde la inscripción en el Registro Mercantil de la sociedad, el socio que hubiera votado a favor de la distribución de los beneficios sociales tendrá derecho de separación en el caso de que la junta general no acordara la distribución como dividendo de, al menos, un tercio de los beneficios propios de la explotación del objeto social obtenidos durante el ejercicio anterior, que sean legalmente repartibles. 2. El plazo para el ejercicio del derecho de separación será de un mes a contar desde la fecha en que se hubiera celebrado la junta general ordinaria de socios. 3. Lo dispuesto en este artículo no será de aplicación a las sociedades cotizadas". 
posible ejercicio, votación del socio a favor del reparto de beneficios y base de cálculo del porcentaje legal mínimo) y, por tanto, válidos para el ámbito propio de los socios no trabajadores de las sociedades laborales ${ }^{13}$.

\section{Causas estatutarias de separación en las sociedades laborales}

El artículo 347 LSC admite, como se sabe, que los estatutos sociales puedan establecer otras causas de separación distintas de las legales (indicando el modo de acreditar la existencia de la causa, la forma de ejercitar el derecho y el plazo para su ejercicio). Exigiendo que, para su incorporación, modificación o supresión sea necesario el consentimiento de todos los socios). Por su parte, el artículo 8.1 LSLyP regula (como hacía el extinto artículo 9.1 Ley 4/1997), un buen ejemplo de esa naturaleza, cuando impone la obligación de incorporar el derecho de separación, si los estatutos sociales incorporan cláusulas que prohíban la transmisión voluntaria de acciones o de participaciones sociales por actos inter vivos. Su incorporación exigirá el consentimiento de todos los socios.

Ante la existencia de cláusulas estatutarias de intransmisibilidad plena, como contrapartida por la imposibilidad de exigencia de vinculaciones perpetuas del socio a la sociedad, prohibidas por nuestro ordenamiento jurídico -artículo 1705 Cc-, se reconoce el derecho de separación (que podrá ejercitarse en cualquier momento y sin alegación de causa alguna). Ello les proporciona un mayor grado de liquidez, al permitirles obtener el valor de su participación en la sociedad consecuencia del ejercicio del derecho de separación y salva la dificultad de la ausencia de un mercado para la transmisión de tales títulos, pero está presente, como se verá, el inconveniente de la situación económica en la que se encuentre la sociedad laboral para poder hacer frente al valor razonable de la participación del socio en la sociedad y su posible repercusión sobre la calificación de la sociedad (Sáez García de Albizu, Goñi Sein, De la Hucha Celador y Pérdices Huetos, 2000).

No obstante, el artículo 8.2 LSLyP (también, el extinto artículo 9.2 Ley 4/1997) prevé que los estatutos puedan impedir la transmisión voluntaria de acciones o de participaciones por actos inter vivos, o el ejercicio del derecho de separación, durante un plazo máximo de cinco años a contar desde la constitución de la sociedad, "...o para las acciones o participaciones procedentes de una ampliación de capital, desde el otorgamiento de la escritura pública de la ejecución"-. Dicha suspensión temporal encuentra justificación, tradicional, en orden a la consolidación de la sociedad laboral en el mercado, si bien ha sido planteada la

13 La SAP de Barcelona de 26 de marzo de 2015 advirtió sobre el carácter equivoco y confuso de los presupuestos para el ejercicio del derecho de separación. La doctrina mercantil los ha puesto en duda y ha apuntado propuestas de mejora respecto de la redacción del vigente artículo 348 bis LSC. Recientemente, Alvarez Royo-Villanova, S. y Fernández del Pozo, L. (2017) Una propuesta de redacción alternativa del artículo 348 bis LSC. La Ley Mercantil, No 33, passim. Marina García-Tuñon, A. (2017) Los derechos al dividendo y de separación a la luz del art. 348 bis de la Ley de Sociedades de Capital: una revisión general. Revista de Derecho de Sociedades, No 49, passim. Cañabate Pozo, R. (2017) La defensa del socio minoritario por falta de distribución de dividendos. Revista de Derecho de Sociedades, No 50. Cañabate Pozo, R. y Rojo Ramírez, A. (2017) ¿De la tiranía del accionista de control a la tiranía del socio minoritario?. Revista Española de Capital Riesgo, núm. 1, pp. 5-18. Pulgar Ezquerra, J. (2017) Reparto legal mínimo de dividendos: protección de socios y acreedores (solvency test). Revista de Derecho Bancario y Bursátil, $\mathrm{N}^{\mathrm{o}}$ 147, pp. 149-155. 
opción de reducir ese plazo a tres años, por motivo de restar liquidez a las acciones o participaciones de las sociedades laborales y el poco sentido de alargar situaciones de tal naturaleza, habiéndose ampliado el destino del fondo especial de reserva para poder recomprar las acciones a los trabajadores, artículo 14.2 LSLyP (Diez Acimas, 2016).

En éste terreno, frente al régimen general de las sociedad capitalistas en donde tales cláusulas estatutarias sólo alcanzan las sociedades de responsabilidad limitada, artículo 108.3 y 4 LSC, por su carácter esencial de sociedad cerrada, la LSLyP amplía su ámbito de aplicación a las sociedades anónimas laborales (Sáez García de Albizu, Goñi Sein, De la Hucha Celador y Pérdices Huetos, 2000), por virtud de su configuración laboral que excepciona, una vez más, el régimen de las sociedades capitalistas y el carácter esencial abierto de la sociedad anónima.

\section{La exclusión de socios en las sociedades laborales}

Frente al ejercicio del derecho de separación de los socios dentro de los términos legales o, en su caso, estatutarios establecidos para las sociedades laborales y que supondrá el abandono voluntario del socio de la sociedad, la exclusión de los socios de la sociedad laboral produce el mismo abandono, pero en contra de su voluntad, encontrándose ligada al incumplimiento por parte de los socios de las obligaciones legales o, en su caso, estatutarias establecidas. Tradicionalmente había sido concebida como una sanción al socio, precisamente por encontrarse vinculada a causas imputables al propio socio, aunque se ha reconducido hacia mecanismos de resolución de conflictos entre socios (Fernández de Córdoba, 2013; Alfaro Aguila-Real, 1997; Alfonso Sánchez, 2016), y de pervivencia pacífica de la sociedad.

A esos efectos, el artículo 16.3 LSLyP regula ex novo, frente al régimen derogado, las causas legales que posibilitan la exclusión de los socios de las sociedades laborales. Dichas causas encuentran su fundamento en el incumplimiento de determinadas obligaciones exigidas por el legislador a sus socios en los ámbitos siguientes: transmisión de acciones y de participaciones sociales y realización de actividades perjudiciales para los intereses de la sociedad cuando hubieran sido condenados por sentencia firme a indemnizar a la sociedad por los daños y perjuicios causados.

Por lo tanto, se trata de causas especiales de exclusión de socios en las sociedades laborales que, de un lado, no están vinculadas a la forma jurídica de la sociedad laboral (sociedad anónima o sociedad de responsabilidad limitada) y que, de otro lado, se extienden a todos los socios de la sociedad laboral (socios trabajadores y socios no trabajadores de la sociedad laboral).

Dichas causas especiales no impiden las previstas en el artículo 350 LSC para las sociedades de responsabilidad limitada laborales así como, de conformidad con el artículo $351 \mathrm{LSC}^{14}$, las posibles causas estatutarias de exclusión de socios que,

14 En las sociedades de responsabilidad limitada constituyen causas legales de exclusión de socios las siguientes: incumplimiento voluntario de la obligación de realizar prestaciones accesorias, infracción por parte del socio administrador de la prohibición de competencia y la condena al socio administrador por sentencia firme a 
tanto para sociedades anónimas como para sociedades de responsabilidad limitada laborales, hayan sido previstas con el consentimiento de todos los socios. El mismo consentimiento será exigido para la modificación o supresión de las causas de exclusión estatutarias existentes.

Así, el incumplimiento de las obligaciones para los socios en materia de transmisión de acciones o de participaciones (fundamentalmente, artículos 6 a 12 LSLyP, que incluye los supuestos de transmisión voluntaria por actos inter vivos, los supuestos de extinción de la relación laboral y la transmisión mortis causa), que se puede considerar pieza esencial de su nuevo régimen jurídico favorecedor del acceso a la condición de socio a los trabajadores por tiempo indefinido, y la realización de actividades perjudiciales para los intereses de la sociedad existiendo condena por sentencia firme a indemnizar los daños y perjuicios causados a la sociedad laboral, conforman la relación de causalidad entre la conducta no debida de los socios y la exclusión de la sociedad. En el ámbito propio de las causas legales de exclusión para sociedades de responsabilidad limitada, artículo 350 LSC, el socio administrador se ve afectado, también, por causa de exclusión cuando por actos contrarios a la ley o a los estatutos o realizados sin la debida diligencia hubieran sido condenados por sentencia firme a indemnizar a la sociedad los daños y perjuicios causados. Parece, por lo tanto, un ámbito subjetivo más amplio y no ligado a actuaciones contrarias a la ley o a los estatutos o sin la debida diligencia aunque refiere, en concreto, actividades perjudiciales a los intereses de la sociedad, lo que sin duda pueda dar lugar a situaciones de conflicto, que son las que se pretenden evitar.

No obstante lo dicho, la exclusión requiere, como se sabe, del acuerdo de la junta general (así, artículo 16. 4 LSLyP y artículo 352.1 LSC, respecto del procedimiento de exclusión de socios) por lo que estando presentes sus causas es necesario el acuerdo de la sociedad laboral (anónima o limitada) para poder excluir al socio (acuerdo concreto e independiente para cada socio) ${ }^{15}$. Al respecto, se advierte, además, en la nueva regulación que, de un lado, en relación al incumplimiento de las obligaciones en materia de transmisión de acciones o de participaciones, la sociedad laboral tiene que consentir cualquier transmisión de acciones o de participaciones cuando puedan superarse los límites previstos en el artículo 1.2 LSLyP y que los transmitentes deben comunicar a la sociedad los términos de la transmisión lo que puede potenciar el cumplimiento de las obligaciones exigidas y que, de otro lado, habiendo sido condenado el socio a indemnizar a la sociedad los daños y perjuicios causados por actividades perjudiciales para los intereses de la sociedad laboral, ésta puede entender superada la situación de conflicto planteada y no acordar la exclusión del socio.

indemnizar a la sociedad los daños y perjuicios causados por actos que sean contrarios a la Ley o a los estatutos o realizados sin la debida diligencia.

15 En la sociedad de responsabilidad limitada el acuerdo tiene que ser adoptado por mayoría reforzada de, al menos, dos tercios de los votos correspondientes a las participaciones en las que se divide el capital social (artículo 199 b LSC), quedando excluidas para ese cómputo las participaciones del socio que se pretende excluir (artículos 190.2 y 190.1,b LSC) y que, además, tiene suspendido el derecho de voto pero no otros derechos inherentes a su condición de socio, como el de asistencia y participación en la deliberación de los puntos del orden de día. En la sociedad anónima el acuerdo sólo exige el quórum ordinario y ninguna mayoría especial (artículos 193 y 201 LSC) y tiene suspendido, igualmente, el derecho de voto (artículo 190.1,b LSC) pero no el de asistencia y participación en la deliberación de los puntos del orden de día. 


\section{Efectos para la sociedad laboral derivados del ejercicio del derecho de separación y de la exclusión de socios}

Tanto en los supuestos de separación como en los de exclusión de socios se producen efectos relevantes para la sociedad laboral que, desde el punto de vista económico y del correspondiente a las reestructuraciones subjetivas que implica, pueden afectar a la propia existencia de la sociedad laboral.

En las sociedades laborales, frente al régimen general para las sociedades capitalistas, se exige que las acciones o participaciones de los socios separados o excluidos sean ofrecidas a los trabajadores de la sociedad con contrato de trabajo por tiempo indefinido, conforme a lo previsto en el artículo 6 LSLyP. Por su parte, las que no sean adquiridas deberán ser amortizadas mediante reducción del capital social, artículo 16.3 LSLyP. No tiene cabida para las sociedades laborales el régimen previsto en el artículo 359 LSC (Mateo Hernández, 2016).

La sociedad laboral, además, queda obligada a la restitución del valor de las acciones o de las participaciones transmitidas o amortizadas que se erige como un derecho del socio separado o excluido. Éste derecho se hará efectivo en el plazo máximo de cuatro meses a partir de la recepción del escrito por el que el socio comunica a la sociedad el ejercicio del derecho de separación en los supuestos de pérdida de la calificación, del acuerdo de la junta general que decide la exclusión, o de la notificación de la resolución judicial firme dictada al respecto, artículo 16.4 LSLyP $^{16}$.

Así, constituyen aspectos relevantes en el ámbito de la separación y de la exclusión de socios, la novedad de éste régimen de transmisión así como el propio de la valoración de las acciones o de las participaciones sociales, no sólo por incorporarse ex novo al régimen jurídico vigente para las sociedades laboral, frente al régimen extinto, sino también porque dista del régimen propio de las sociedades capitalistas.

En primer lugar, y con la pretensión de fortalecer la condición laboral de la sociedad, se ha modificado el régimen de transmisión voluntaria inter vivos de acciones o de participaciones sociales y, en lo que ahora concierne, las acciones o participaciones de los socios separados o excluidos serán ofrecidas a los trabajadores de la sociedad con contrato de trabajo por tiempo indefinido dando, así, cumplimiento a una de las finalidades de la nueva regulación de facilitar el acceso de los trabajadores a la condición de socio ${ }^{17}$. Dicho ofrecimiento $-a$ los trabajadores de la sociedad con contrato de trabajo por tiempo indefinido- se hará conforme a lo previsto en el artículo 6 LSLyP que regula, como se sabe, el derecho de adquisición preferente en caso de transmisión voluntaria inter vivos de acciones o participaciones y que diferencia entre los supuestos de transmisión libre, artículo 6.1 LSLyP y, los demás supuestos, artículo 6.2 LSLyP. Por ello, no tratándose éste de un supuesto de transmisión libre, la remisión general que se hace al artículo 6

16 Por su parte, la LSC sólo refiere un plazo de dos meses para la obtención por parte del socio separado o excluido del valor razonable de su participación en la sociedad para el supuesto amparado en el artículo 356.1 LSC, es decir, en el plazo de dos meses siguientes al informe de valoración del experto externo independiente.

17 Frente a éste marco legal de la LSLyP, el artículo 188.3 RRM posibilita que, vía estatutos sociales, se pueda imponer al socio la obligación de transmitir sus participaciones sociales a los demás socios o a terceras personas cuando concurran circunstancias expresadas de forma clara y precisa en los estatutos. 
LSLyP debe entenderse referida al apartado 2 del artículo 6 LSLyP y circunscrita, exclusivamente, a los trabajadores indefinidos no socios. De ese modo, no opera el ofrecimiento de las acciones o participaciones del socio separado o excluido ni a favor de socios trabajadores (artículo 6.2.2 ${ }^{\circ}$ LSLyP), ni de socios de la clase general (artículo 6.2.3 ${ }^{\circ}$ LSLyP), ni tampoco, finalmente, de la sociedad (artículo 6.2.4 $4^{\circ}$ LSLyP. Sólo en favor de los trabajadores indefinidos no socios (artículo 6.2.1 ${ }^{\circ}$ LSLyP).

Para ello, se sigue el procedimiento diseñado en el artículo $6.2 \mathrm{LSLyP}^{18}$, más ágil y rápido que el régimen derogado (García, 2017) y, caso de concurrencia de trabajadores con contrato de trabajo a tiempo indefinido serán priorizados en relación directa a su antigüedad en la empresa, artículo 6.2.1 ${ }^{\circ}$ LSLyP. Además, para evitar superar los límites tipológicos que determinan la condición laboral de la sociedad (artículo 1.2 LSLyP), toda transmisión de acciones o de participaciones (sea de la clase que sea: general o laboral) queda sometida al consentimiento de la propia sociedad, artículo 6.3 LSLyP ${ }^{19}$.

Las acciones o participaciones que no sean adquiridas serán amortizadas y operará, como en el régimen de las sociedades capitalistas, la correspondiente reducción de capital.

En segundo lugar, respecto de la valoración de las acciones o participaciones se ha previsto, como novedad relevante respecto del régimen derogado ${ }^{20}$, la posibilidad de que los estatutos sociales establezcan los criterios y sistemas de determinación previa de su valor para los supuestos de transmisión o amortización, en cuyo caso prevalecerá dicho valor. Y, si tal posibilidad se produjera una vez constituida la sociedad, no sería de aplicación a los socios que no votaron a favor del acuerdo de modificación de los estatutos, artículo 7 LSLyP. Esto último, merece ser destacado ya que, carece de precedentes en el ámbito de las sociedades de capital y podría dar lugar a una valoración diferente para las acciones o participaciones sociales en función de si el socio se ve o no afectado por la cláusula estatutaria que establezca los criterios o sistemas de determinación previa de su valor, ya que los socios disidentes no están vinculados sine die por las mismas

18 El procedimiento de articula de la siguiente forma: el socio separado o excluido comunicará a la sociedad el número, características términos económicos de las acciones o participaciones a transmitir y ésta trasladará la propuesta en el plazo máximo de diez días simultáneamente a todos los trabajadores indefinidos no socios de la sociedad, quienes en el plazo máximo de veinte días desde la notificación de la transmisión proyectada deberán manifestar su voluntad de adquisición. Una vez recibidas las ofertas de compra, los administradores cuentan con un plazo de diez días para comunicar al transmitente la identidad del adquirente o adquirentes, quienes en su caso, serán priorizados en caso de concurrencia.

19 Asimismo, la adquisición por parte de los trabajadores de la sociedad con contrato de trabajo por tiempo indefinido de las acciones o participaciones de los socios separados o excluidos puede suponer un cambio de clase, por lo que “...los administradores sin necesidad de acuerdo de la Junta General procederán a formalizar la modificación del artículo o artículos de los estatutos a los que ello afecte, otorgando la pertinente escritura pública que se inscribirá en el Registro Mercantil, una vez inscrita en el Registro de Sociedades Laborales.

20 El artículo 8 Ley 4/1997, de 24 de marzo de sociedades laborales se refería, también, al valor real de las acciones o participaciones sociales frente al valor razonable del artículo 7 LSLyP, entendiéndose por aquel "... el que determine el auditor de cuentas de la sociedad y, si ésta no estuviera obligada a la verificación de las cuentas anuales, un auditor designado a este efecto por los administradores". Ahora, el valor razonable viene determinado por "...el que determine un experto independiente, distinto del auditor de la sociedad, designado a este efecto por los administradores". Los gastos que ello ocasione siguen siendo, como antes, de cuenta de la sociedad cuentas salvo si en las enajenaciones siguientes, durante el mismo ejercicio anual, el transmitente o adquirente no aceptan ese valor razonable (antes, valor real), en cuyo caso se podrá practicar nueva valoración a su costa. 
(Verdú, 2016). No obstante la referida posibilidad estatutaria, el valor de las acciones o participaciones sociales a efectos de su transmisión a los trabajadores indefinidos no socios será el convenido y comunicado al órgano de administración por el socio transmitente, artículo 7, párrafo primero LSLyP. El valor de reembolso de las acciones o participaciones operará respecto de las que no sean adquiridas por los trabajadores indefinidos no socios de la sociedad laboral.

Por su parte, no puede olvidarse la situación económica en la que se encuentra la sociedad para poder atender al cumplimiento o ejecución del derecho de separación o de exclusión, que requiere, como se ha dicho, la entrega al socio en el domicilio social del valor de sus acciones o participaciones transmitidas o amortizadas, artículo 16.4 LSLyP, y que podría acarrear la descapitalización de la sociedad (y, entrar a valorar la necesaria protección de acreedores sociales, Pulgar Ezquerra, 2017), e incluso, la disolución societaria. La propia caracterización de la sociedad como laboral, tampoco, puede olvidarse sobre todo en el supuesto del ejercicio del derecho de separación por todos los socios que, en su caso, pueden ejercerlo: todos los socios en los supuestos de descalificación forzosa de la sociedad laboral y todos los socios que no votaron a favor del acuerdo de descalificación en el supuesto de la descalificación voluntaria (Lázaro Sánchez, 2017), así como, todos los socios no trabajadores en el supuesto amparado por el artículo 348 bis LSC, que han quedado al margen del ámbito subjetivo del artículo 16.2 LSLyP. Por ello, la doctrina ha puesto de manifiesto la necesidad de que el ejercicio del derecho de separación sea atemperado con la exigencia de fidelidad del socio y el límite del ejercicio abusivo del derecho de separación (Sáez García de Albizu, Goñi Sein, De la Hucha Celador y Pérdices Huetos, 2000; Pulgar Ezquerra, 2017). La exclusión de socios requiere, también, sus cautelas aunque el acuerdo necesario para la exclusión pueda salvarlas. Pero adoptado el acuerdo operará el ejercicio de la acción de expulsión por parte de la sociedad o, en su defecto, por parte de cualquier socio que hubiera votado a favor de la expulsión, artículo 352 LSC.

Sin duda, como ha sido advertido, todo ello exige importantes reestructuraciones subjetivas, que afectan a la estructura interna societaria (también, a la esfera externa por la necesaria protección de acreedores sociales) y que, como se ha dicho, pueden hacer peligrar la caracterización laboral de la sociedad e, incluso, su propia pervivencia. De ahí, la importancia de anticiparse la sociedad laboral a los efectos derivados del ejercicio del derecho de separación y de la exclusión de socios.

\section{Referencias Bibliográficas}

Alonso Ledesma, C. (2013) La autonomía de la voluntad en la exclusión y separación de socios. Revista de Derecho Mercantil, No 287, pp. 89-128.

Alfonso Sánchez, R. (2016) Estatuto jurídico del socio (II). Separación y exclusión. En: Derecho de Sociedades de Capital. Estudios de la Ley de sociedades de capital y de la legislación complementaria, Embid Irujo, J.M., (Dir.), Madrid: Marcial Pons, pp. 205224.

Alvarez Royo-Villanova, S. y Fernández del Pozo, L. (2017) Una propuesta de redacción alternativa del artículo 348 bis LSC. La Ley Mercantil, No 33, p.1. 
Alfaro Aguila Real, J. (2011) Derecho de separación del socio en caso de sequía de dividendos: el nuevo artículo 348 bis de la Ley de Sociedades de Capital, $C / M / S$, Albiñana\&Suárex de Lezo.

Alfaro, J. y Campins, A, (2014) Abuso de la mayoría en el reparto de dividendos y derecho de separación del socio en las sociedades de capital. En: Liber Amicorum a Juan Luis Iglesias Pradas, coords., por Javier García de Enterría y Lorenzo Velázquez. Madrid: Civitas.

Andreu Martí, M.M. (2013) Consideraciones sobre la propuesta de reforma de la Ley de Sociedades Laborales. En: Economía Social y Derecho. Problemas jurídicos actuales de las empresas de economía social, Gómez Manresa, M-F., y Pardo López, M., (Dirs./Coords.). Granada: Comares.

Barrero Rodríguez, E. (2015) Consideraciones sobre la reforma del régimen legal de las sociedades laborales. Revista de Derecho de Sociedades, No 45, pp. 249-289.

Cáceres Carceles, C. (2012) El ejercicio de derecho de separación del socio en caso de no distribución de dividendos. Las reformas introducidas por el artículo 348 bis LSC. Derecho de los Negocios, No 263-264, pp. 29-42.

Calvo Ortega, R. (2013) Sociedades Laborales. Madrid: Civitas.

Campuzano, A.B. (2011) Derechos del socio. En: Comentarios a la Ley de Sociedades de Capital, Tomo I y II, Rojo, A., y Beltrán, E., (coords.). Madrid: Civitas.

Cañabate Pozo, R. (2017) La defensa del socio minoritario por falta de distribución de dividendos. Revista de Derecho de Sociedades, № 50.

Cañabate Pozo, R. y Rojo Ramírez, A. (2017) ¿De la tiranía del accionista de control a la tiranía del socio minoritario?. Revista Española de Capital Riesgo, núm. 1, pp. 5-18.

Cavas Martínez, F. y Selma Penalva, A. (2011) El estatuto jurídico-profesional de los socios trabajadores en la proyectada reforma de las sociedades laborales. Ciriec-España. Revista Jurídica de Economía Social y Cooperativa, № 22, pp. 181-215.

Ciruela-Lorenzo, A.M.; Cuadrado Serrán, M. y Plaza Angulo, J.J. (2016) La economía social como alternativa de autoempleo. El perfil del emprendedor/a en las sociedades laborales andaluzas". REVESCO. Revista de Estudios Cooperativos, Tercer Cuatrimestre, No. 122, pp. 59-85. DOI: 10.5209/rev_REVE.2016.v122.52019.

Diez Acimas, L. (2016) Régimen jurídico de las sociedades laborales y participadas (análisis de la Ley 44/2015. De 14 de octubre). Deusto Estudios Cooperativos, No 8. pp.51-96.

Fernández de Córdoba Claros, I. (2013) La separación y exclusión de socios en las sociedades de capital. Revista de Derecho de Sociedades, No 41, pp. 281-330.

Fernández de la Gandara, L. (2010) Derecho de Sociedades, Vol. II. Valencia: Tirant lo Blanch.

García Ruiz, E. (2013) El régimen legal de las sociedades laborales sometido a revisión. Revista de Derecho de Sociedades, № 41, pp. 249-280.

García Ruiz, E. (2017) El régimen societario de las sociedades laborales en la nueva Ley 44/2015, de 14 de octubre, de Sociedades Laborales y Participadas. REVESCO. Revista de Estudios Cooperativos, Primer Cuatrimestre, $\mathrm{N}^{\mathrm{o}} 123$, pp. 64-93.

García Sanz, A. (2012) Derecho de separación en caso de falta de distribución de dividendos. Revista de Derecho de Sociedades, No 38, pp. 55-72.

García Valdecasas, J.A. (2015) Resumen de la Ley de Sociedades Laborales y Participadas. https://www.notariosyregistradores.com/web/secciones/oficina-mercantil/otros-temas-om/resumen-de-la-ley-de-sociedades-laborales-y-participadas/.

Gómez Calero, J. (1999) Las Sociedades Laborales. Granada: Comares. 
González Castilla, F (2012) Reformas en materia de separación y exclusión de socios. En: Las reformas de la Ley de Sociedades de Capital (Real Decreto-Ley 13/2010, Ley 2/2011, Ley 25/2011 y Real Decreto-ley 9/2012), Rodriguez Artigas, F., Farrando Miguel, I., González Castlla, F., (dirs.), Pamplona: Aranzadi, pp. 243-317.

Lázaro Sánchez, E.J. (2017) Calificación y descalificación de sociedades laborales: coordinación entre el Registro Administrativo y el Registro Mercantil. La Ley Mercantil, $\mathrm{N}^{\mathrm{o}} 36$, pp. 1-9.

Marina García-Tuñon, A. (2017) Los derechos al dividendo y de separación a la luz del art. 348 bis de la Ley de Sociedades de Capital: una revisión general. Revista de Derecho de Sociedades, No 49, pp. 27-60.

Mateo Hernández, J.L. (2016) Hacía una mayor participación de los trabajadores en la realidad empresarial a través de la nueva regulación de las sociedades laborales. Revista de Derecho de Sociedades, № 46, pp. 1-10.

Neila Neila, J.M. (1998) Sociedades Laborales. Análisis sistemático de la Ley 4/1997, de 24 de marzo. Madrid: Dykinson.

Olavarría Iglesia, J. (2008) Algunos aspectos societarios de la propuesta de reforma de la Ley de sociedades laborales presentada por Confesal. Ciriec-España. Revista Jurídica de Economía Social y Cooperativa, № 19, pp. 1-5.

Pagador López, J. (2005) Las Sociedades Laborales. La Sociedad de Garantía Recíproca. En: Tratado de Derecho Mercantil, Tomo XII, Vol. 2. Madrid: Marcial Pons.

Paniagua Zurera, M. (2004) Recensión al libro de Cano López, A., Teoría jurídica de la economía social. La sociedad laboral: una forma jurídica de empresa de economía social. Revista de Derecho Mercantil, № 252.

Paniagua Zurera, M. (2015a) La singularidad tipológica de la sociedad laboral y su legislación adecuada. (A propósito de la Proposición de Ley de Sociedades Laborales de Confesal y de la aplicación judicial de la Ley 4/1997, de Sociedades Laborales). Revista de Derecho de Sociedades, No 44, pp. 171-232.

Paniagua Zurera, M. (2015b) Las sociedades laborales ante el Anteproyecto de Ley de nuevo Código Mercantil. En: Estudios sobre el fututo Código Mercantil, libro homenaje al profesor Rafael Illescas Ortiz. Getafe: Universidad Carlos III de Madrid, pp. 726744.

Pulgar Ezquerra, J. (2017) Reparto legal mínimo de dividendos: protección de socios y acreedores (solvency test). Revista de Derecho Bancario y Bursátil, N ${ }^{\circ}$ 147, pp. 139176.

Rodríguez Ruiz de Villa, D. (2012) La batalla por los dividendos en las sociedades de capital (primeras reflexiones a la luz del artículo 348 bis de la Ley de Sociedades de Capital). Cuadernos de Derecho y Comercio, No 57, pp. 201-228.

Ruiz Peris, I. (2002) Breves reflexiones en materia de sociedades laborales y acceso de los trabajadores a la propiedad de los medios de producción. En: Libro homenaje al profesor Sánchez Calero, Vol. IV. Madrid: McGraw Hill.

Sáez García de Albizu, J.C.; Goñi Sein, J.L.; De La Hucha Celador, F. y Perdices Huetos, A.B. (2000) Sociedades Laborales (Ley 4/1997, de 24 de marzo). En: Comentario al régimen legal de las sociedades mercantiles, Tomo XV, Uría, R., Menéndez, A., y Olivencia, M., (Dirs.). Madrid. Civitas.

Saldaña Villoldo, B. (2016) Tipos Especiales (II). Sociedades Profesionales y Laborales. En: Derecho de Sociedades de Capital. Estudios de la Ley de Sociedades de Capital y de la legislación complementaria, Embid Irujo, J.M., (Dir.). Madrid: Marcial Pons. 
Santos Martínez, V. (2002) Sociedades laborales: implantación y renovación de una peculiar figura societaria. En: Libro homenaje al profesor Sánchez Calero, Vol. IV. Madrid: McGraw Hill.

Santos Martínez, V. (2007) Transmisiones de las acciones y participaciones sociales laborales. En: Estudios de Derecho de Sociedades y Derecho Concursal. Libro homenaje al profesor Rafael García Villaverde, Tomo II. Marcial Pons, pp. 1269-1308.

Silva Sánchez, M. J. y Sambeat Sastre, J.M. (2012) Análisis y crítica del artículo 348 bis de la Ley de Sociedades Capital. Diario La Ley, No 7825, de 26 de marzo de 2012, y Diario La Ley, $\mathrm{N}^{0} 7844$, de 24 de abril.

Valpuesta Gastaminza, E. y Barberena Belzunce, I. (1998) Las Sociedades Laborales. Aspectos societarios, laborales y fiscales. Pamplona.

Vázquez Lépinette, T. (2012) La separación por justa causa tras las recientes reformas legislativas. Revista de Derecho Mercantil, No 283, pp. 169-196.

Verdú Cañete, M.J. (2016) La configuración de las sociedades laborales como entidades de economía social. Novedades de la Ley 44/2015, de 14 de octubre, de Sociedades Laborales y Participadas. Revista Lex Mercatoria, No 1, pp. 144-149.

Zarzalejos Todedano, I (2015) Derecho de separación en caso de falta de distribución de dividendos. La Ley Mercantil, № 16. p. 5. 